\title{
La utopía de fray Jacobo el Danés y su lucha por un clero indígena
}

\author{
Alberto Carrillo Cázares* \\ EL COLEGIO DE MICHOACÁN
}

El presente trabajo se dirige a contextualizar, dentro de la obra evangelizadora de la Iglesia mexicana del siglo xvi, el esfuerzo del franciscano danés, fray Jacobo Daciano, por defender los derechos religiosos de los indígenas a quienes, habiendo recibido el bautismo, se les negaba la recepción de los demás sacramentos, especialmente el sacerdocio, por razones raciales contrarias a la práctica de la primitiva Iglesia de los apóstoles. Este último Provincial de la Orden Seráfica en Dinamarca, expulsado de su país a raíz de la introducción del protestantismo en su patria, pasó a Espańa y de España a México en 1542, destinado a la Custodia de su Orden en Michoacán. Su sueño evangélico quedó diseñado en una obra latina y castellana titulada Declamación del pueblo bárbaro de los indios que habiendo recibido el bautismo desea recibir los demás sacramentos, que despertó una fuerte controversia dentro de su misma Orden. Su memoria se conserva viva a través de más de cuatro siglos en los pueblos indígenas de Zacapu y de Tarecuato en Michoacán.

(Derechos religiosos de los indígenas, clero indígena, historia y utopía)

U

no de los misioneros más clarividentes sobre la forma como se iba fundando la Iglesia indiana, fue el fraile danés Jacobo Daciano (c. 1484-1566), evangelizador de la Provincia franciscana de Michoacán en el siglo xvi. Ante el extraordinario desarrollo de la conquista espiritual de este Nuevo Mundo, la carencia de ministros para atender las crecientes necesidades de la nueva cristiandad se convirtió en un problema pastoral que pedía

*acarrillo@colmich.edu.mx 
urgente remedio. La solución propuesta por fray Jacobo Daciano consistía en que se comenzara la pronta y eficaz formación de un clero escogido entre la misma población indígena. La propuesta sin embargo encontró una fuerte e invencible oposición. El presente trabajo tiene la finalidad de ofrecer una revisión -poco atendida en la historiografía de la Iglesia indiana- de la propuesta teológica y pastoral del franciscano danés en favor de los derechos religiosos de los cristianos indígenas y de la creciente oposición del episcopado y de las mismas órdenes religiosas a la admisión de candidatos nativos al sacramento del orden.

Las contradicciones que surgieron en el proceso de la evangelización fundante fueron contundentes. Por una parte se requerían pastores para la grey indígena y por otra se negaba el acceso a los naturales que podrían desempeñar ese ministerio. Prevaleció la opción de importar clérigos, tanto en las órdenes religiosas, como en los primeros obispos y en los concilios provinciales mexicanos y limeños. A continuación exponemos algunos testimonios, que bastarán para compulsar la intensidad de esa actitud.

El primer obispo de México, don fray Juan de Zumárraga para proveer a este socorro en 1537, se ofrecía a pagar el pasaje de Espańa a México de los ministros que tanto se necesitaban:

Y si se hace lo que aquí digo de dar Tezcuco como está en corregimiento, sin que haya corregidor por los seis ańos, yo aceptar[é] la pensión de dar cada año trezientos ducados, para el pasaje de los fraires, al visorrey, y así, viniendo cada años quinze o veinte fraires, se hinchará la tierra dellos y no se qué mejor población; y sería asegurar la tierra - y en no venir fraires desmayan los que acá están, que a la verdad trabajan mucho, ni es en su mano trabajar poco; sea v.m. en esto, en que vengan muchos. ${ }^{1}$

Los franciscanos reunidos en Capítulo en Guadalajara en mayo de 1552 escriben al emperador manifestando la gran necesidad que la nueva Custodia desprendida de la Provincia del Santo Evangelio

${ }^{1}$ Carta de Fr. Juan de Zumárraga a Juan de Sámano, Secretario de s.M. México el 20 de diciembre de 1537. Cartas de Indias, México, sнCP 1980. Facsímile de 1877, p. 172. 
de México, tiene de obreros evangélicos para Michoacán y Jalisco diciendo que como "hay tan gran falta de religiosos suplicamos a v.M. por amor de Nuestro Señor sea servido de mandar y dar orden cómo para esta nueva custodia del Nuevo Reino de Galicia vengan por lo menos cient frailes [...] y que sean dirigidos para esta Nueva Custodia del Reino de Galicia y Mechuacan, porque es la parte donde mayor fruto se espera". ${ }^{2}$

Firma esta carta fray Jacobo Daciano, como uno de los cuatro definidores, junto con el custodio, fray Ángel de Valencia. Seis años más tarde, en 1558, el segundo arzobispo de México, fray Alonso de Montúfar, abogaba por el envío de clérigos de España al servicio de los obispados, aunque exagerando según su estilo:

Muy fácil cosa sería, con mediana diligencia que se tuviese, en cada armada enviar doscientos o trescientos clérigos escogidos por las universidades y cibdades principales, que allá no tienen de comer, como se ha pedido por mi antecesor y obispos y por vuestro consejo real prometido, si con ellos se hiciese, como ay obligación y vuestra Majestad la tiene, lo que se hace con los religiosos en ayudalles para el camino. ${ }^{3}$

La incorporación de eclesiásticos de la Vieja a la Nueva Espańa tenía sus graves peligros, por la oportunidad que se daba a clérigos aventureros de pasar a estas partes no a hacer apostolado, sino fortuna fácil con gran daño de la misma Iglesia. Los religiosos fueron muy incisivos en denunciar este desorden, pero los mismos obispos lo sufrían y lo lamentaban. Fray Martín de Hojacastro, segundo obispo de Tlaxcala, lo resumía así:

En los clérigos que a estas parte pasan por la mayor parte se descubren grandes flaquezas y se ven grandes escándalos, porque o han sido frailes o vienen huyendo de sus prelados y por maravilla hay quien de todos ellos

${ }^{2}$ Cartas de Indias, p. 104, firman el Custodio Fray Ángel de Valencia y, entre los 4 definidores, Fray Jacobo Daciano.

${ }^{3}$ AGI, Indiferente 2978: Parecer del Arzobispo de México al Rey. México 11 de enero de 1558, apud Francisco Miranda, Don Vasco de Quiroga y su Colegio de San Nicolás, 2a. ed., Morelia, umsnH, 1990, 92. 
entienda medianamente gramática [esto es latín] y lo peor es que todos vienen movidos de la desordenada codicia y no los trae el zelo de la fe, de donde se sigue que siendo ydiotas y fugitivos y en grande manera cobdiciosos no tratan las cosas de la fe y sacramentos con la sciencia que se requiere ni con la limpieza y libertad y aplicación necesarias. ${ }^{4}$

En pocas palabras advertía el primer virrey don Antonio de Mendoza a su sucesor don Luis de Velasco: "Los clérigos que vienen a estas partes son ruines y todos se fundan en interés y si no fuese por lo que S.M. tiene mandado y por el bautizar, por lo demás estarían mejor los indios sin ellos. Esto es en general, porque en particular algunos buenos clérigos hay". 5

Quedaba el recurso de ir a buscar a España y escoger los clérigos buenos que quisieran venir. Esto lo puso en práctica don Vasco de Quiroga, pero se topaba con la limitación de lo poco que les podía ofrecer en las mismas canongías de su incipiente obispado, donde los mismos ya nombrados se quejaban de la poca monta de las prebendas. El arcediano que don Vasco dejó en Pátzcuaro durante su larga ausencia de casi siete años en España, ocupado en pleitos y providencias para su diócesis, escribía el 12 de marzo de 1549 a su prelado suspirando por algo mejor: "Lo que más tengo que suplicar a V. Sría. Revma. es que se acuerde de sus servidores y criados, que dexó en esta Santa Iglesia, y que vea V. Sría. lo poco que valen estas prevendas que no hay prevendado que quiera venir a servir por el poco salario que hay" ${ }^{6}$

\section{EL PROYECTO DE ESTUDIOS MAYORES PARA LA FORMACIÓN DE MINISTROS CRIOLLOS}

La raíz de una solución más completa no escapaba a la inteligencia de ninguno de estos entendidos prelados, que sabían que estribaba no en importar, sino en producir sus propios sacerdotes y ministros

${ }^{4}$ Agr, Audiencia de México 336. Apud Francisco Miranda, op. cit., p. 81.

${ }^{5}$ Instrucciones y Memorias de los Virreyes novohispanos, t. I., México, 1991, 99.

${ }^{6}$ Nicolás León, El Ilmo. Sr. D. Vasco de Quiroga..., Morelia, umsnh, 1984, 327. 
criollos de estas mismas tierras. Esta fórmula de solución fue puesta en práctica desde el primer momento al fundar las Órdenes sus estudios mayores y noviciados en estas sus provincias, y en dar comienzo Zumárraga en México a la Real Universidad y, en Michoacán, don Vasco al Real Colegio de San Nicolás.

Hay que destacar que el fin primero y fundamental de estas instituciones promovidas y fundadas por la Iglesia era precisamente la formación adecuada de los ministros de la Iglesia a imagen y semejanza de las nobles universidades del Viejo Mundo: Salamanca, Alcalá, París o Bolonia.

los padres criarían a sus hijos en esta Universidad y colesio así por el recogimiento de ellos, que no sería poco fruto, y viendo que ay beneficios en que proveer sus hijos y colesio y Universidad en que criarse, harían estudiar a sus hijos, y como todos los que en esta tierra se crían son lenguas y como naturales no ternían deseo de irse a España, cesarían las cobdicias y los clérigos que de allá vienen para luego volverse; y en breve tiempo esta tierra ternía de su propia cosecha los ministros y lenguas que oviese menester, como ya tenemos algunos hordenados de la propia tierra, hijos de esta Universidad. $^{7}$

Los estudiantes que aspiraran a las órdenes sagradas vivirían y recibirían la debida atención en colegios anexos a la universidad o a las catedrales. El oidor Montealegre así lo proponía expresamente:

Los colegios, a mi ver, son también necesaríssimos que o residieren en esta Universidad o en cada cabecera de obispados, para que, en ellos, demás de los hijos legítimos de los españoles, algunos mestizos pudiesen ser doctrinados y aprender las lenguas que en cada obispado ay, señalando prebendas de cada lengua, para que siendo de edad salgan de allí sacerdotes y lenguas. Todo esto por la mejor orden que a los que en estas partes governaren y prelados pareciere. ${ }^{8}$

${ }^{7}$ AGI, Indiferente 2978, Fray Alonso de Montúfar al Consejo. México 30 de noviembre de 1554, apud Francisco Miranda, op. cit., p. 104.

${ }^{8}$ AGI, Indiferente 2978. Parecer del Doctor Montealegre, apud Francisco Miranda, op. cit., p. 107. 
Esta providencia la tenía ya tomada en Michoacán el obispo Quiroga. A ese intento estaba dirigida la fundación de su Colegio de San Nicolás, cuyo ordenamiento claramente definía en su testamento el gran gobernante de esta diócesis:

Primeramente: declaramos que a muchos años que yo fundé en esta ciudad de mechoacán, en el varrio de pásquaro, cerca de nuestra yglesia catedral de sant salvador, el colesio de sant niculás, que aquí está fundado, por la gran falta de ministros de los santos sacramentos y culto divino, que aquí y en todo nuestro obispado de mechuacán a havido e ay; que sean presvíteros clérigos; así para que aquí en este dicho colegio se rrecivan y críen estudiantes, puros españoles, que pasen de más de veinte ańos, que quieran ser hordenados y sean lengoas; y así hordenados de todas hórdenes, suplan algo de la gran falta dicha de ministros, como siempre después acá, loable y útilmente criado, estudiado y hordenado, y dado de sí buen exemplo e ayudado e servido, en esta nuestra dicha santa yglesia e obispado, muchos, y otros en rreligión y con mucho fruto y utilidad, como se a visto e vee de cada día por la experiencia. ${ }^{?}$

\section{UN CLERO NATIVO, COMO SOLUCIÓN PARCIAL}

Todo esto apuntaba ya a la formación de un clero nativo, en el sentido de un clero local no importado de fuera. Es sumamente importante señalar este horizonte abierto de la primitiva Iglesia indiana.

Este clero nativo era ya un paso de grande alcance para la consolidación de la Iglesia y de la sociedad. Tenemos que recordar que las instituciones de estos dominios de España no estaban, por lo menos, bajo el dominio de los Austrias, proyectadas como colonias, sino como vicerreinos, que se estructuraban a imagen y semejanza de los reinos de Castilla: su gobierno, sus colegios y universidad, la administración de justicia, el ordenamiento económico y tributario, y sobre todo la Iglesia misma, obispados y provincias de las órdenes religiosas, se criaban y conformaban al modelo de España. No es

${ }^{9}$ Nicolás León, op. cit., p. 178. 
extraño que el mismo clero, en lo que toca a su formación, su estilo y sus personas se pensaran y se realizaran en este marco: sus ministros serían sacados de entre los candidatos destinados a ejercer funciones de dirigentes dentro de la Iglesia. ¿Dónde se hallaban tales candidatos? Se hallaban entre los hijos de los espańoles, sobre todo si eran pobres, como sucedía en la península, quienes pensaban lograr buen acomodo en la Iglesia según el refrán: "Iglesia, mar y casa real, quien quiera medrar". Por eso Don Vasco no tiene empacho en asentar que sus colegiales han de ser "puros españoles".

A los principios, la cuestión de admisión a órdenes sacros de colegiales indios no se plantea, porque no los hay. No se excluyen, indios puros pero tampoco se les incluye. De hecho en las erecciones de iglesias catedrales se tomaba en cuenta esta posibilidad, de tener ordenados indios, pero se aplazaba para más adelante su promoción a beneficios eclesiásticos:

Queremos y estatuimos que se provean [los beneficios] tan sólo entre los hijos patrimoniales descendientes de los vecinos que pasaron de España a la dicha provincia o que en lo venidero pasen a poblarla, hasta que vista y reconocida por nosotros o por nuestros sucesores la cristiandad y capacidad de los indios, a instancia y petición del susodicho patrón [el Rey] que ahora o en lo venidero existiere, pareciere que los beneficios puedan proveerse también a los indios, hecho antes el examen y la oposición según la forma y laudable costumbre observada en la diócesis de Palencia. ${ }^{10}$

Lo mismo prevenía el primer virrey don Antonio de Mendoza, cuando asentaba que los estudiantes indios, aun cuando fueran letrados y virtuosos, no se admitieran al sacerdocio, porque este privilegio se debía reservar para cuando esta nación llegara a un nivel de civilidad semejante a la española; y mientras tanto los hijos de los espańoles que supieran la lengua fueran los elegidos para la ordenación sacerdotal. ${ }^{11}$

${ }^{10}$ Rafael Aguayo Spencer, Don Vasco de Quiroga. Documentos..., México, 1939, 239.

${ }^{11}$ Instrucciones y memorias..., D. Antonio de Mendoza, p. 101. 


\section{LA FORMACión DE COLEgIALES INDÍGENAS: El COLEgIO DE Santa Cruz de Tlatelolco: utopía y Contradicción}

En esa edad de oro de la evangelización del país también se soñó, como es sabido, con la formación de una elite indígena paralela a la nobleza india, que se pudiera educar en el nivel de los estudios de las universidades y colegios de España, y para ello se fundó el célebre Colegio de Santa Cruz de Tlatelolco, que aunque no estaba diseñado expresamente como un seminario para clérigos, sí lo era para la formación de los hijos de los principales, que enseñados en las humanidades clásicas sirviesen de enlace con los prelados y religiosos para apoyar la evangelización y por su medio comunicar a los naturales las cosas de la fe con la seguridad que la ortodoxia y la responsabilidad eclesial requería. Tal objetivo se conseguiría, si lograban los obispos y los enseñados en tal colegio hablar una misma lengua, como el latín. Esto lo expresaba muy bien el primer obispo de México fray Juan de Zumárraga:

Los obispos desta Nueva España [...] aviendo platicado largamente, concordamos en aquellos capítulos que escrivimos a v.M.; todo ello encomendamos, pues son cosas que importan y le cabrá parte del mérito ante Dios [...] y por la cuenta estrecha que avemos de dar a Dios y le debemos a nuestro Rey desta carga tan pesada que tomamos a cuestas, y mayormente en no entender a éstos de quien se nos ha de pedir estrecha cuenta, a mí me paresce cosa tan rezia, que, cuando lo pienso, me tiemblan las carnes. ¿Qué cuenta podré yo dar de quien no lo entiendo ni me entiende, ni puedo conoscer su conciencia? Y por eso aviendo platicado los obispos cerca desta materia, venimos en esta sentencia, que no se podía hallar al presente otro medio mejor, que enseñar a éstos lengua latina, en que nos pudiésemos entender, pues nosotros, especialmente yo en mi vejez, no puedo aprender la suya; y que por estos que enseñamos, daremos a entender mejor lo que queremos dezirles a nuestras ovejas los pastores, y que cada uno dellos, bien fundados primero en la religión cristiana, desde chiquitos, con medianas letras, serán antes creydos en la condenación de sus errores y vanidades y ritos gentílicos que tenían, tan fuera de razón, y harán mucho mayor fruto que agora hazen muchos religiosos, porque vemos que los mayores todavía 
están en sus treze y quieren tener y no dexan, sino por fuerza, los ydolos y ritos acostumbrados, especial de tener muchas mugeres; poca enmienda sentimos, y en los casamientos que se han hecho, muy poca permanencia. ${ }^{12}$

Este proyecto se concreta en el Colegio de Santa Cruz de Tlatelolco para colegiales indios, hijos de los principales mexicanos, de tan altas miras como la utopía de los hospitales-pueblos de Vasco de Quiroga, sólo que, a diferencia de los hospitales, el noble colegio no tuvo sino una tan efímera como gloriosa existencia.

El Imperial Colegio de la Santa Cruz de Santiago Tlatelolco (1533, 1536-1576) fue el más avanzado y noble proyecto de formación de jóvenes indígenas de la nobleza mexicana encaminada a la preparación de estudiantes que pudieran un día llegar a la ordenación sacerdotal. Fundado el 6 de enero de 1536 fue un proyecto franciscano propuesto por el obispo fray Juan de Zumárraga, apoyado por el presidente de la Audiencia don Sebastián Ramírez de Fuenleal, por el recién llegado primer virrey don Antonio de Mendoza, y realizado con generosidad por lo más granado de los letrados de la orden seráfica. El colegio acogió en sus comienzos a unos sesenta alumnos, escogidos entre los hijos de los señores y principales de los mayores pueblos y provincias de la Nueva Espańa, trayendo allí dos o tres de cada cabecera o pueblos principales, a fin de que se extendiera a todos el beneficio del estudio. Al estilo hispano, los colegiales portaban las insignias de colegial, hopa o sotana con beca, y observaban un horario conventual que incluía el rezo de las horas de nuestra Seńora, la misa mańanera, la comida en el refectorio y el reposo en dormitorio común, bajo la custodia de un celador. Los colegiales estudiaban lectura, escritura y música, y eran enseñados en la lengua latina, hasta hablarla y escribirla según las reglas de la retórica, estudiaban lógica, filosofía y aun medicina indígena

Con los religiosos de la Orden de San Francisco, -escribía al Emperador el obispo Ramírez de Fuenleal- he procurado que enseñen gramática [esto es

${ }^{12}$ El obispo Zumárraga a Juan de Sámano. Secretario de s.M., México 20 de diciembre de 1537. Cartas de Indias, México, SHCP, 1980. Facsímile de 1877, 168-169. 
lengua latina], romanzada en lengua mexicana a los naturales [...] porque sabida alguna gramática y entendiéndola, serán menester personas que les lean [en cátedra] libros de buena latinidad y oratoria, y por esto bastará que los maestros sean instruidos en la lengua latina, aunque no sean frailes nahuatatos ni sepan su lengua, pues en latín se han de leer y doctrinar (1533. 8 de agosto). ${ }^{13}$

Mendieta da cuenta de que se enseñaba, además de las humanidades latinas, lógica, filosofía y parte de teología, con "notables y gravísimos maestros; en la latinidad después de fray Arnaldo de Bassacio a fray Bernardino de Sahagún y a fray Andrés de Olmos, en la retórica, lógica y filosofía al doctísimo fray Juan de Gaona”. ${ }^{14}$

Los frutos del colegio fueron óptimos, saliendo de sus aulas excelentes latinos, y aun catedráticos de indios y de frailes, y oficiales de república tan entendidos como don Antonio Valeriano, que fue gobernador de la ciudad de México por más de 30 ańos, traductores de los libros de doctrina y ayudantes de los mismos impresores de ellos, auxiliares de los ministros en examen de los matrimonios y administración de los otros sacramentos, muchos eran elegidos, por su misma suficiencia, jueces y gobernadores en la comunidad indígena.

Pronto acabó tan noble ejercicio y el colegio decayó acabándose sus protectores, Zumárraga, Fuenleal, Mendoza y Sahagún. A los nuevos gobernantes, por celos y envidias, les comenzó a parecer "por mal empleado todo el bien que se les hace a los indios y por tiempo perdido el que con ellos se gasta". ${ }^{15}$ Los argumentos pretextados: $1^{\circ}$ que el saber latín los indios de ningún provecho era para la república, aunque la experiencia mostraba lo contrario; $2^{\circ}$ que podrían dar en herejías y errores, bastantes para alborotar a los pueblos, cosa que jamás sucedió, fuera del caso del juicio seguido contra don Carlos, Señor de Texcoco, por supuesta herejía. En este embate contra sus mismos pupilos, tampoco faltaron religiosos que les fueron contra-

${ }^{13}$ Mariano Cuevas, Historia de la Iglesia en México, t. I, p. 386.

${ }^{14}$ Gerónimo de Mendieta, Historia eclesiástica indiana, II, Madrid, BAE, 1973, 41-42.

${ }^{15}$ Ibidem. 
rios. "Y también los ministros de la Iglesia desmayados y el fervor y calor muerto, y así se ha ido todo cayendo, no las paredes del Colegio (que buenas y recias están...) sino el cuidado, fervor y calor que tengo dicho". ${ }^{16}$

Hacia 1576 se desvanecía aquella inspiración y esperanza de la Iglesia indiana, que podría haber fructificado en un excelente clero indígena. El colegio de Tlatelolco no dio a México un solo sacerdote de nación india.

\section{LA POLÍTICA ANTIINDIGENISTA}

La solución a la necesidad imperiosa de ministros para esta nueva Iglesia por medio de un clero indígena se iba tornando remota e impracticable. Definitivamente los que llevaban ahora las riendas de la Nueva España, encabezados por el nuevo arzobispo de México, fray Alonso de Montúfar, se opusieron a la posibilidad de ver a indios hechos frailes o eclesiásticos dotados de saber y poder espiritual.

Obispos, oidores, prelados de órdenes religiosas, incluidos los franciscanos, que tanto trabajo y favor habían dado al Imperial Colegio de Santa Cruz de Tlatelolco, todos a una cerraron filas con el partido hostil a los indios y prohibieron formalmente no sólo dar las órdenes sagradas a los indígenas, sino aun admitirlos a la profesión religiosa.

Los argumentos fueron generalizaciones tan extremas como la supuesta incapacidad para asumir autoridad, "no son para mandar sino para obedecer", la desventaja de ser nuevos en la fe, y por tanto inmaduros para perseverar, y sobre todo la general inclinación de la gente indígena a la embriaguez.

No vamos a entretenernos en discutir la insustancialidad, ahora ya patente, de tales argumentos. Nos parece más importante señalar lo que parece que era la causa más potente que movía el fondo de la argumentación en contra de la aceptación de los indios al estado eclesiástico y religioso. So color de razones teológicas o inconve-

${ }^{16}$ Ibidem. 
niencias morales, se movía una intención política de mantener todo el poder en manos de los espańoles. Lo mismo la clase gobernante del virreinato, que los prelados de la Iglesia secular y regular, decidía mantener los intereses del dominio de la tierra, por encima de las exigencias del reino de los cielos.

Políticas de gobierno, necesidades de consolidar la autoridad episcopal, conveniencias de dirigir el destino de las órdenes religiosas, sumadas a una visión enmarcada en la tradición y la cultura netamente hispana, cerraron en el siglo Xvi el acceso de los indios "por muy sabios y virtuosos que fueren" ${ }^{17}$ a la dignidad sacerdotal. Una especie de ceguera general impidió a tan ilustres prelados, entre ellos al jurista don Vasco, mirar lo que hacían al negar a los naturales de estas tierras aquello por lo que la Iglesia estaba clamando para su misma consolidación: ministros dispensadores de los misterios divinos.

\section{El eXtraordinario proyecto de fray Jacobo Daciano}

Providencialmente, el único que superando las limitaciones de la cultura dominante europea, y las conveniencias del poder conquistador, se atrevió a denunciar el yerro de la Iglesia indiana de negar a los indios los sacramentos, fue fray Jacobo Daciano, franciscano, teólogo eminente, exprovincial de larga experiencia pastoral, y hombre de gran nobleza y virtud, que ocupó el cargo de guardián del convento de Pátzcuaro y Zinzunzan, gran conocedor de la lengua y el alma indígena e incansable evangelizador de la tierra michoacana hasta su santa muerte en Tarecuato en 1566.

Desde su llegada a Michoacán en 1542, y a pesar de la prohibición sancionada por un Concilio de Lima y mantenida por la generalidad del clero indiano, fray Jacobo de Dacia, fue en su orden el primero en admitir a la comunión a los indios, a quienes se les negaba so pretexto de verlos tiernos en la fe y no probados en virtud.

Este franciscano "gran letrado extranjero" (Mendieta) había pasado de España, en la primavera de 1542. En el registro de embar-

${ }^{17}$ Instrucciones y memorias..., D. Antonio de Mendoza, loc. cit. 
que en Sevilla se le nombraba Provincial de Dacia, esto es de la Provincia Franciscana de Dinamarca. Expulsados de aquellos reinos de escandinavia, los franciscanos lo tuvieron como último Ministro Provincial, que defendió los derechos de la Orden y de la Iglesia católica esforzadamente contra los asaltos de los reformadores luteranos. Era miembro de la familia real reinante en Dinamarca-Suecia-Noruega, hermano menor del rey Cristián II, quien se había hecho al bando protestante. Optando por el destierro, Jacobo de Dacia halló refugio para sí y para sus frailes en la comarca alemana de Mecklenburgo, donde dispuso las cosas de la extinta Provincia de Dacia, y partió luego para Espańa con destino a un Nuevo Mundo. El emperador Carlos V le dio cartas de recomendación para el virrey de la Nueva España.

En abril de 1542 se hizo a la mar en Sevilla en la nave La Trinidad y desembarcó en Veracruz. El 14 de agosto siguió viaje de este puerto a la ciudad de México. Y destinado a Michoacán desplegó un ministerio admirable en el corazón del reino tarasco, desde el convento franciscano de Pátzcuaro cabeza de la diócesis recién instaurada por Don Vasco, cinco ańos atrás (1538). A su virtud probada en la persecución, añadía un profundo conocimiento de la teología y la sagrada escritura. Dominaba el griego y el hebreo, a más del latín, y pronto fue experto en la lengua de Michoacán, al grado de que el arzobispo de México, 10 años adelante, lo escogería para revisar y dar aprobación a las obras de fray Maturino Gilberti.

La identidad y la obra de este extraordinario franciscano evangelizador de Michoacán, cuya memoria se conserva viva y tierna en Zacapu y Tarecuato, consta en todas las crónicas franciscanas y ha sido esclarecida en nuestros días por las exhaustivas investigaciones del historiador danés, Jorgen Nybo Rasmussen, cuya obra ha sido traducida y publicada por el Colegio de Michoacán.

Fue este misionero danés el que, en medio de la general resignación, levantó la voz para hacer conscientes a prelados y religiosos del yerro en que incurrían al negar a los bautizados los demás sacramentos y fue el único que se atrevió a denunciar la negativa de la ordenación sacerdotal a los indígenas como una de las más graves deficiencias en la implantación de la fe en estas tierras. 


\section{LA TeOlogía de fRAY JaCobo de Dacia}

La tesis fundamental de la teología del danés sostenía que la administración de los sacramentos era el sustento de la vida de la Iglesia y que concedido el bautismo a los creyentes, su misma salud espiritual requería ser sustentada por la donación de los demás sacramentos sin distinción de raza. Mendieta resume la conclusión de este gran letrado extranjero en estos términos: "que esta Nueva Iglesia indiana iba errada por no tener ministros naturales de los convertidos, como la Iglesia primitiva; teniendo esta opinión que a los indios se debían dar órdenes sacros y hacerlos ministros de la Iglesia”. ${ }^{18}$

Con sólidos argumentos el teólogo danés escribió un libro que hizo estremecer a frailes y clérigos. Su título mismo denota su fuerza: Declamación del Pueblo Bárbaro de los Indios que habiendo recibido el Bautismo desean recibir los demás Sacramentos. ${ }^{19}$ En esta obra el eminente teólogo se atrevía a advertir que "la Iglesia mexicana no se iba fundando in Spiritu Sancto" (Mendieta) puesto que "fundar la fe de Jesucristo sin suficientes ministros y sin dar los sacramentos necesarios para la salvación, es fundar la fe sin el Espíritu Santo" ${ }^{20}$

La denuncia de la negativa de dar los sacramentos a los bautizados indios incluía en lugar primerísimo la causa que originaba la falta de ministros, esto es la ordenación sacerdotal de candidatos indígenas.

Por el testimonio del bibliógrafo José Mariano Beristáin de Souza sabemos que fray Jacobo escribió dos libros, uno en castellano que vio Beristáin todavía a principios de siglo pasado en la biblioteca del Convento de Tlatelolco, cuyo título, ya citado, era Declamación de los indios... El otro en latín, sin duda dirigido a prelados y religiosos, especialmente a sus propios hermanos de orden, en el cual presentaba en forma académica sus tesis y su cuestionamiento sobre lo que estaba sucediendo con la administración de los sacramentos a los indígenas convertidos, que eran la casi totalidad de la nueva Iglesia indiana.

${ }^{18}$ Gerónimo de Mendieta, op. cit., p. 61.

${ }^{19}$ José Mariano Beristáin de Souza, Bibliotheca Hispano-Americana Septentrional, México, 1816-1821. Ed. facsímile, t. I., México, unAM, 1981, 420-21.

${ }^{20}$ Ibidem. 


\section{El DESOlador PANORAMA DE CARENCIA DE SACRAMENTOS DENUNCIADO POR FRAY JACOBO DACIANO}

El manifiesto teológico y pastoral del exprovincial de Dinamarca, ponía en tela de juicio la recta fundación de la Iglesia indiana debido a una culpable carencia de sacramentos a los convertidos.

El argumento, como todos sabían, se apoyaba en la forma lamentable en que se estaban negando los sacramentos a los naturales, entre ellos la Confirmación por la cual se debía derramar precisamente la abundancia del Espíritu Santo a los bautizados. Esto era resultado de la falta de obispos. Asunto tan grave no estaba siendo considerado suficientemente ni por la Iglesia ni por la Corona. Sin embargo, nadie podía alegar ignorancia de lo que estaba sucediendo. El provincial franciscano, fray Francisco de Toral, cinco años después del debate que vamos a presenciar, podía escribir con una franqueza sin tapujos:

Agora han faltado los perlados sanctos y zelosos, por lo qual hay gran baja y jactura, que en trezientas leguas no hay más que dos, que son el señor arzobispo de México y el Obispo de Mechuacan. Este señor es viejísimo y no atiende en cosa de órdenes ni de sacramentos, sino en pleitos y diezmos. El seńor arzobispo que está más mozo y podría ayudar, no quiere porque no le dan los diezmos los naturales; también hay gran necesidad de religiosos porque si nos acabamos, y no envía v.A. quien quede en nuestro lugar, todo se perderá. ${ }^{21}$

Así andaban las cosas respecto al sacramento de la confirmación. Acerca del mismo bautismo había grandes estorbos para su administración. Los testimonios de Pátzcuaro, que constan en el pleito del clero diocesano contra los franciscanos, en que el clérigo Diego Pérez Gordillo, brazo derecho del obispo Quiroga, les quebró a los religiosos la pila bautismal del convento, cuna de la cristiandad michoacana, dejan ver algo de este escenario erizado de dificultades: “ $\mathrm{y}$

${ }^{21}$ Carta de Fr. Francisco de Toral, provincial de la Orden de San Francisco al Consejo de las Indias, México 25 de mayo de 1558. Cartas de Indias, p. 132. 
sabe este testigo [fray Juan Bautista] que los dichos religiosos por la dicha vejación y molestia de haberles quebrada la pila y impedirles los sacramentos han sido muy vejados y molestados y desde entonces han sido estorbados e impedidos en la administración de los dichos sacramentos en el dicho monesterio de esta ciudad". ${ }^{22}$

La administración del sacramento de la confesión no se menciona en los extractos de Beristáin, pero el cronista de Michoacán, fray Diego Muñoz, hace hincapié en que fray Jacobo "no negaba ni dilataba el sacramento de la Penitencia a muchos españoles que se venían a confesar con él". 23

La comunión poco se daba a los espańoles y generalmente se negaba a los indios. Todos los cronistas franciscanos y los testimonios de los indígenas de Pátzcuaro están concordes en reconocer que fue fray Jacobo Daciano el primero en admitir a los indios a la sagrada comunión "Fue el primero - escribe Mendieta- que administró a los tarascos el santísimo sacramento de la Eucaristía". ${ }^{24}$

En cuanto al sacramento de la extremaunción, Beristáin de Souza nos ha conservado el texto mismo correspondiente a la argumentación de fray Jacobo en su libro latino:

¿Y qué diré de la extremaunción? Ya salió mandamiento de México para que no se le administre a ninguno de los indios; aunque el Padre Martín (el venerable Martin de Valencia) dignísimo Comisario General a nosotros nos ha dado la facultad de administrarla, mas aún el Apóstol Santiago, Legado de Nuestro Señor Jesucristo, en su Epístola nos instruye ¿̨Alguno entre vosotros enferma? etc. [Haga llamar a los presbíteros de la Iglesia y oren sobre él ungiéndole con óleo en el nombre del Señor...] (Jac. 5, 14). ${ }^{25}$

Según Beristáin “sobre cada uno de los Sacramentos pone el Padre Daciano sus reparos". La administración del matrimonio -cosa

${ }^{22}$ AGI, Justicia, Legajo 178, Ramo 2. Año de 1573. Testimonio de Fray Juan Bautista, 1 de julio de 1573 .

${ }^{23}$ Fray Diego Muñoz, "Memorial de la Provincia de San Pedro y San Pablo de Michoacán”, Archivo Ibero-Americano, Madrid, 1922, 397.

${ }^{24}$ Gerónimo de Mendieta, op. cit., II, p. 19.

${ }^{25}$ José Mariano Beristáin de Souza, Bibliotheca Hispano-Americana Septentrional, México, 1816-1821, Ed. facsímile t. I, unAM, México 1981, 420. 
en la que no entran los cronistas de la Orden- constituía también un quebradero de cabeza para clérigos y ministros doctrineros, sobre todo, por el centralismo del Provisor, en el caso de Michoacán, y de toda la administración quiroguiana que dificultaba tanto la absolución de impedimentos -ya de por sí tan numerosos en el Derecho Canónico pretridentino-. Por ejemplo, el impedimento de afinidad tan multiplicado y frecuentemente oculto, tanto que los naturales que querían ser casados sacramentalmente o se quedaban sin el sacramento o lo recibían en el fuero de la conciencia, dando lugar a los llamados matrimonios clandestinos, cuestión que enfrentó en una guerra intestina a los clérigos oficiales rigoristas con los religiosos que, usando de los privilegios papales, concedían las dispensas y casaban a los indios que lo pedían. Apenas podemos imaginar la confusión creada por esta cuestión que casi paralizaba la administración del matrimonio a los indígenas.

El tema central, sin embargo, estribaba en la tesis más atrevida del Daciano, la que planteaba como solución la ordenación de un clero indígena: "que a los indios se debían dar órdenes sacros y hacerlos ministros de la Iglesia" ${ }^{26}$

Fray Jacobo partía de una sólida teología bíblica y pastoral, como lo ha hecho ver el historiador danés Jorgen Nybo Rasmussen, en el más serio estudio que se ha publicado hasta hoy sobre la teología del franciscano danés, después de lo que escribieron sobre su virtud y ciencia los cronistas franciscanos de los siglos XVI y XVII. Este mismo investigador expresa muy bien la gravedad del sentido implícito en la denuncia de fray Jacobo:

Si la escasez de sacerdotes no hubiera sido, sino un hecho dado, fray Jacobo no habría elaborado ningún argumento teológico. Sólo que, por desgracia, se era culpable de tal escasez, pues no se quería ordenar a ningún indio. Ahí estaba la verdadera raíz del mal, la causa de que la administración de los demás sacramentos -como él mismo ya lo había señalado- se hubiera descuidado tan lamentablemente. En efecto, no sólo no se había querido ordenar a ningún indio, sino que precisamente en ese tiempo, en

${ }^{26}$ Gerónimo de Mendieta, op. cit., p. 61. 
los Concilios de Lima y de México, como fray Jacobo naturalmente sabía, se había pensado en cerrar las puertas a la posibilidad de tal ordenación, por una prohibición eclesiástica aun con apoyo del derecho canónico. Con lo cual se introducía en esta nueva iglesia no sólo una práctica perjudicial, sino un principio herético: el de la desigualdad de las razas, desconocido para la Iglesia primitiva, la Iglesia del Nuevo Testamento. ${ }^{27}$

Teológicamente, como señala Rasmussen, el Daciano consideraba que una vida sacramental completa era la base indispensable para que los naturales hechos ya cristianos llegaran a la madurez cristiana que sus mismos críticos reclamaban de ellos. Aquí reside lo peculiar de su tesis. Esto lo distingue de sus mismos hermanos de orden. Jacobo toma en serio a San Pablo: "no hay griego ni judío, circuncisión ni incircuncisión, bárbaro o escita, siervo o libre, porque Cristo lo es todo en todos" (Colos. 3:11). Grandes protectores de los indios, como el mismo don Vasco, Gaona, Sahagún, Mendieta, consentían en la exclusión sacramental de los indios, no por mala voluntad probablemente, sino por un juicio (o prejuicio) basado en generalizaciones de carácter pastoral y so color de razones teológicas argüían en estos nuevos cristianos, inhabilidad para el mando, inconsistencia en la vocación, e invencible inclinación al vicio de la embriaguez.

\section{LA APOLOGÍA DE LO ESTABLECIDO Y EL ENJUICIAMIENTO DE FRAY JACOBO}

El libro, del exprovincial de Dacia, manuscrito, por supuesto, como se estilaba a la sazón, corrió de mano en mano, produciendo los efectos de un temblor de tierra en los medios eclesiásticos y frailunos. La réplica no se hizo esperar. El epicentro de la Declamación de los indios, pronunciada por voz de fray Jacobo, franciscano de la Custodia de los Santos Apóstoles San Pedro y San Pablo, se localizaba en Michoacán. La réplica en cambio vino de la capital de la Nueva España, la ciudad de México. Y no se crea que se alzaba a

${ }^{27}$ Jorgen Nybo Rasmussen, Fray Jacobo Daciano, Zamora, El Colegio de Michoacán, 1992, 89 . 
contradecirlo un miembro de la orden dominicana, tan hostil a los indígenas, ni un Montúfar tan desamorado con los indios, no. Para que la cuña apretara tenía que ser del mismo palo. El que salió a acallar al Daciano fue uno de sus mismos hermanos de hábito, antiguo maestro del Colegio de Santa Cruz de Tlatelolco, antaño amigo también del danés, nada menos que el sabio maestro fray Juan de Gaona. Era éste el más connotado de los teólogos del partido antiindigenista, doctorado en la Universidad de París, antiguo catedrático del Colegio de Santa Cruz de Tlatelolco, y acababa de renunciar al cargo de provincial de México. Su impugnación llevaba un título que en sí denuncia la hostilidad de su réplica: Antidota quarumdum propositionum cuinsdam famigeratissima Theologi, Contraveneno para algunas proposiciones de cierto teólogo que se tiene por muy famoso. ${ }^{28}$

La controversia, prudentemente acallada en las crónicas, y apenas mencionada en su sentencia final contra el Daciano, es posible reconstruirla, en parte, con el material reproducido entre líneas por los mismos cronistas que registraron el debate y la derrota del extranjero. Cuál haya sido el nervio de dicha Apología, lo podemos rastrear en el discurso que a este propósito guardaron las crónicas franciscanas: Gerónimo de Mendieta lo insertó en el capítulo 23 del libro cuarto de su Historia Eclesiástica Indiana y de ahí lo reproduce fray Juan de Torquemada en el capítulo xiII del libro diez y siete de su Monarquí Indiana. Nos han llegado también algunos fragmentos textuales tanto del Libro latino de fray Jacobo, como de la Apología de fray Juan de Gaona, transcritos por el bibliógrafo del siglo xIx, José Mariano Beristáin de Souza, en su Bibliotheca HispanoAmericana Septentrional.

Así, aunque desgraciadamente están perdidos los manuscritos de ambos contendientes, quedó su contenido en parte vertido en estos grandes memoriales.

El debate se entabló al más alto nivel académico y disciplinar. Internarnos en el proceso de este enfrentamiento será asistir a uno de los debates teológicos más dramáticos y acallados de la historia de la Iglesia en México. Meditarlo, nos permitirá respirar el ambiente

${ }^{28}$ Beristáin de Souza, t. II, op. cit., p. 19. 
en el cual, fray Jacobo de Dacia, "uno de los más insignes teólogos que había en todo el Reino", según elogio del mismo Torquemada, ${ }^{29}$ se atrevió a plantear la cuestión del clero indígena y ofrecer una solución que de haber sido aceptada hubiera quizá cambiado todo el proceso histórico de la Iglesia mexicana.

A juzgar por la fecha de la Apología de Gaona, este proceso se lleva a cabo en la ciudad de México el $1^{\circ}$ de mayo del ańo de 1553 , probablemente en el marco del Capítulo de la Provincia del Santo Evangelio. La Orden encargó a su más afanado teólogo rebatir la tesis de fray Jacobo, que no dejaba de inquietar seriamente a los religiosos y al clero en general. El elegido, fray Juan de Gaona, ilustre teólogo de la corte de S.M. y notable maestro en los estudios de la Orden en México, había sido Ministro Provincial en ese mismo trienio de 1551 a 1553, habiendo renunciado sorpresivamente al cargo. No es improbable que el verdadero motivo -a más de sus escrúpulos- haya sido dedicarse a preparar la Apología de la orden ante el "teólogo extranjero". La dedicatoria que Gaona dirige al Provincial, su sucesor, fray Juan de San Francisco, muestra toda la intención de enderezar el entuerto del letrado extranjero, saliendo a la defensa y consuelo de la Orden Seráfica, personificada en el nuevo Provincial, su inmediato sucesor. Empieza, en efecto, con esta patética frase: Antidotos a algunas proposiciones de cierto dizque afamadísimo teólogo, dedicados al muy Reverendo Padre fray Juan de San Francisco, ministro provincial de la Provincia de Santo Evangelio: Cuán largos y cuántos trabajos y sufrimientos te han bañado de sudores, Padre nobilísimo... ${ }^{30}$

Beristáin no conservó más que esta frase introductoria, pero no es difícil entender cuánto lamentaba el apologista Gaona que frente a tan conocidos apostólicos sudores se alzara el clamor de la Declamación del Pueblo Bárbaro de los indios en la voz de fray Jacobo de Dacia, a cuyo atrevimiento era menester oponer pronto y eficaz remedio y antídoto. Comienza así el debate contra tamańas proposiciones de quien desde este momento es calificado, según el lenguaje escolástico, como el adversario:

${ }^{29}$ Torquemada, libro veinte, cap. LIII, op. cit.

${ }^{30}$ Beristáin de Souza, t. II, op. cit., p. 19. 
Primer argumento daciano: el ejemplo de la Iglesia primitiva. "Prima adversarii propositio: Fundare fidem Jesu-Christi sine sufficientibus ministris et sine usu Sacramentorum ad salutem necessariorum est fundare fiden sine Spiritu Sancto: Fundar la fe de Jesucristo sin suficientes ministros y sin dar los sacramentos necesarios para la salvación, es fundar la fe sin el Espiritu Santo" [Es asi que esta Iglesia en las Indias Occidentales de este modo se va estableciendo, luego esta Iglesia Indiana se está fundando sin el Espiritu Santo]. ${ }^{31}$

\section{Gaona replica:}

"A lo que respondió el P. Gaona conviviendo en la doctrina y explicándola en cuanto a los hechos: Esta nueva Iglesia plantada en el nuevo mundo de las Indias, ha sido plantada por el Espíritu Santo; y al calor del mismo Espíritu crece día con día en el Señor recibiendo aumento de su vigor en Cristo Jesús" ${ }^{32}$ Sobre las otras proposiciones de Fray Jacobo y antídotos de fray Juan Beristáin sólo anota como dijimos: "sobre cada uno de los Sacramentos pone el P. Daciano sus reparos y a todos satisface Fray Juan de Gaona larga, docta y nerviosamente". ${ }^{33}$

Segundo argumento daciano: la vocación ministerial de los indios. "Hermano vos decís que los Indios comunmente tienen muchas condiciones e inclinaciones naturales muy apropiadas para ayudarlos a ser buenos cristianos, y habéis traído ejemplos particulares de indios a quien Dios comunicó su Espíritu, que tuvieron deseo de servirle, renunciando al mundo y siguiendo la vida evangélica. Pues ¿̨qué es la causa, porque a estos tales no se les dará el hábito de la religión, no solamente para legos, más aún para sacerdotes, como en la primitiva Iglesia se elegían los gentiles y judíos nuevamente convertidos a la fe, para sacerdotes y obispos?” 34

${ }^{31}$ Ibidem.

${ }^{32}$ Ibidem.

33 Ibidem.

${ }^{34}$ Esta cita y todas las siguientes, de esta argumentación, pertenecen al texto de Gerónimo de Mendieta, Historia Eclesiástica Indiana, cap. 23, libro cuarto, reproducido al pie de la letra por Juan de Torquemada, Monarquía indiana, cap. xiII del libro diez y siete. 
Réplica gauniana:

"A esto bastaba responder brevemente confesando que así pasó en la primitiva Iglesia, y que entonces así convenía, porque Dios obraba con milagros en aquellos recién convertidos, y así eran santos y se ofrecían luego al martirio, por la confesión del nombre de Jesucristo. Mas en estos tiempos, la iglesia, alumbrada por el Espíritu Santo y enseñada con la experiencia de muchos reveses que se han visto en los nuevos cristianos, tiene ordenado, por determinación de los Sumos Pontífices Vicarios de Cristo, que no se admitan a la profesión de las religiones los descendientes de cualesquiera infieles en el cuarto grado, y esto mismo tiene ordenado nuestra religión en sus estatutos".

Segundo argumento de la tesis de Fray Jacobo: la conveniencia de predicar al pueblo indígena la fe en su propia lengua y atender a una mejor aceptación del Evangelio.

"Y parece sería esto de provecho para la conversión y buena cristiandad de toda su nación, por saber ellos mejor sus lenguas para predicarles y administrarles en ellas más propia y perfectamente, y el pueblo tomaría y recibiría la Doctrina de boca de los naturales con más voluntad que de los extraños".

Réplica de Gaona: Primer argumento en contra, el peligro de reincidencia:

"Y ańado, que puesto caso [la fórmula latina de respuesta en el discurso escolástico reza: Addo, quod, dato, non conceso...] que no se presumiese en alguna manera que habían de volver al vómito de los ritos y ceremonias de su gentilidad (que es por donde la Iglesia se mueve a privarlos de ese beneficio a los recién convertidos) hay en ellos más causa que en otros descendientes de infieles, para no admitirlos a la dignidad del sacerdocio, ni a la de la Religión, aunque fuese para legos".

Segundo argumento en contra: la incapacidad para el mando "y ésta es un natural extraño que tienen (por la mayor) parte los Indios, diferentes de otras naciones (y aún no sé si participan algunos de los Griegos) que no son buenos para mandar ni regir, sino para ser mandados y regidos en estos tiempos de su cristianismo". 
Tercer argumento en contra: el peligro de engreimiento en la dignidad "Porque cuanto tienen de humildad y sujeción en este estado, como habemos pintado, tanto más se engreirían si se viesen en lugar alto, y así quiero decir que no son para maestros sino para discípulos, ni para prelados sino para súbditos".

Ironía contra fray Jacobo: "y para esto los mejores del mundo".

Cuarto argumento en contra y potissima ratio: el ser viciosos:

"Y la razón que hace más fuerza es que son sujetos a la embriaguez y dados al vino, y por eso no deben ser religiosos".

Contrarréplica de Jacobo Daciano: En su gentilidad no se emborrachaban.

Redarguye Juan de Gaona:

" $y$ dado caso, que en su gentilidad no se emborrachaban (como en otra parte decimos), era por temor que tenían a los que gobernaban, que así lo mandaban en común; pero los viejos bebían, y en las fiestas se emborrachaban".

Nueva prueba daciana: Hay ahora quienes no sólo no se emborrachan pero ni lo beben.

Concesión y contraataque de Gaona:

"Y aunque ahora en particular algunos que no sólo no se emborrachan pero ni lo beben, es en común y en general lo contrario; y por esto se teme que el defecto a que naturalmente se inclinan, no lo pongan en ejecución, siendo profesos en algunas de las Órdenes, o siendo después sacerdotes".

\section{Tercer argumento del Daciano:}

Han sido ya admitidos algunos naturales en las Órdenes, prueba de que en Castilla se tiene otra opinión.

Retuerce Gaona el argumento del caso de Castilla:

"Uno que hubo de cierta Orden en estas partes (aunque por engaño tomó el hábito en Castilla, sin saber que era indio) olía a pez, y bebía cuanto 
podía, y era admirable latino y sabía bien, y era discreto cuanto al buen lenguaje que hablaba; pero tocado de esta rońa y lepra”.

Una prueba más en favor de los indios que aduce Jacobo:

En la orden franciscana tenemos la prueba de religioso indígena franciscano de vida ejemplar.

\section{Excepción que opone Gaona:}

"Verdad sea, que en nuestra Orden ha habido otro, que se recibió en aquellos reinos de Castilla, sin conocerse; pero es muy sobrio, y no se le ha sentido semejante defecto, y siguiendo su natural condición, es pobrísimo, humildísimo y muy penitente, mas no para gobierno; y así no ha sido Guardián, ni ha tenido Oficio (aunque es muy viejo, y hace muchos años que es fraile, y éste en esta virtud es singular, y de singulares dice el Filósofo no hay ciencia); y para dar el hábito o ser sacerdote, no se ha de estar haciendo prueba en muchos para acertar en uno".

\section{Ulterior propuesta de fray Jacobo Daciano:}

Me ofrezco a formarlos idóneos y suficientes para el ministerio sacerdotal.

Escándalo para el auditorio y rechazo de fray Juan por tan temeraria propuesta. Argumento ad Hominem, personal, contra el teólogo extranjero:

“...quien a esto se ofrece, a harto se obliga, y lo tengo por obra de sólo Dios, que los puede trocar y hacer de otro natural, y no de hombres. Y pluguiere a su Divina bondad que esto fuese posible, y lo pudiésemos ver. Mas miren lo que hacen los que en esto se pusieren porque aquellos primeros Pilares que el Señor fue servido de poner por fundamento de su edificio, aunque no presumieron de tanto saber como los modernos, tuvieron el Espíritu del Señor y él los guió y enseñó el modo que habían de tener esta conversión".

Remata Gaona con el estoque de la ley en la mano:

"A algunos de los Indios, criados y adoctrinados de su mano, y al parecer bien inclinados, dieron el hábito de la Orden para probarlos, y luego al 
año de noviciado, conocieron claramente, que no era para ellos y así los despidieron, e hicieron estatuto que no se recibiesen".

Conclusión y aplauso. Gaona víctor, Daciano convicto:

"Un gran letrado extranjero, que pasó de España a estas partes, confiado en su saber, presumió afirmar que esta nueva Iglesia indiana iba errada por no tener ministros naturales de los convertidos como la Iglesia primitiva; teniendo esta opinión que a los Indios se debían dar Ordenes Sacros, y hacerlos ministros de la Iglesia. Y el doctísimo y religiosísimo Padre Fray Juan de Gaona, lo convenció de su error en pública disputa, y lo obligó a que hiciese penitencia. Y esta su Apología, que puso en escrito, está en pie hoy día entre nosotros.

Peroración del campeón:

"Padre Jacobo, religioso, anciano, sacerdote y antaño íntimo amigo mío, con la mayor humildad te ruego nos digas ¡cuál es la causa de que a todos nosotros nos ataques con odio tan acérrimo y nos taches de crimen de pertinacia y herejía?"

\section{CONCLUSIÓN: CANCELACIÓN DEL MÁS CLARO PROYECTO SOBRE EL CLERO INDÍGENA EN LA IGLESIA INDIANA}

La invectiva final es verdaderamente patética y revela toda la carga emotiva -más que teológica- que arrastraba la sentida apología de la hermandad franciscana herida. Ante tal sentimiento, el hombre sabio y santo que era fray Jacobo, traspasado de un dolor más profundo que el de su impugnador, pero dando pruebas de aquella ilimitada caridad que decía San Pablo que "es paciente, es benigna, no es envidiosa, no es jactanciosa, no se hincha, no es descortés, no se irrita, no piensa mal; no se alegra de la injusticia, se complace en la verdad; todo la excusa, todo lo cree, todo lo espera, todo lo sufre" (1 Corintios 13: 4-7), no dudó en dar su brazo a torcer, y así firmó la retractación y aceptó la penitencia que a sus propios superiores les plugo imponerle. Igual que cuando en Pátzcuaro los clérigos de Don Vasco le quebraron la pila bautismal, un vejamen "que le pesó gravemente, y aun le vio llorar" [un testigo] "y fray Jacobo de Daça 
que era un Santo decíales: Forcémonos ¿Qué hemos de hacer sino sufrirlo?"35

¿Porqué fray Jacobo aceptó firmar su retractación? Su historiador Rasmussen, que se plantea esta misma pregunta, responde:

No se puede pensar que fray Jacobo haya firmado su retractación por haber quedado convencido con la argumentación de Juan de Gaona. Se sometió, ciertamente, pero al dictamen del juez competente, esto es, al que había pronunciado el representante de la Provincia de su Orden, reunida en legítimo capítulo. [...] Tal como conocemos hoy día la situación no queda ya oscuro porqué Jacobo aceptó la derrota, firmó la retractación, y al menos por entonces, dejó de luchar. Se reintegró [...] a su actividad misionera en Michoacán, donde no capituló de ninguna manera; sino que quizá esperaba aún circunstancias mejores para retomar la causa. ${ }^{36}$

Así se termina esta revisión historiográfica sobre la más clarividente propuesta a favor del clero indígena hecha por el docto franciscano Jacobo de Dacia, que de haber sido aceptada, acaso hubiera cambiado el rumbo de la historia de la Iglesia indiana.

\section{BiBLIOGRAFÍA}

Aguayo Spencer, Rafael, Don Vasco de Quiroga. Documentos..., México, 1939. Anales de Tarecuato, Anónimo, 2 edición por Vargas Rea en Colección Amatlacuilotl, México, 1951.

Beristain de Souza, José Mariano, Biblioteca Hispano-Americana Septentrional, Amecameca, 1883.

Carrillo Cázares, Alberto, "Un evangelizador de Michoacán. Fuentes y lagunas de ciertos capítulos de Torquemada tocantes a fray Jacobo Daciano", en Relaciones. Estudios de Historia y Sociedad, Zamora, El Colegio de Michoacán, vol. Ix, núm. 33, invierno de 1998, 51-88.

${ }^{35}$ Testimonio de Juan Patze, natural del Barrio de la Concepción de esta Ciudad. 4 de julio de 1573. AGI, Justicia 178, núm.1, Ramo 2 (Cortesía de J. Benedict Warren).

${ }^{36}$ Jorgen Nybo Rasmussen, op. cit., pp. 94-95. 
, "Broder Jakob den Danskes Kamp for indfodte praester" af Dr. Alberto Carrillo Cazares, México, El Colegio de Michoacán. , "Oversat af Astrid Pacheco og Jorgen Nybo Rasmussen", en Historical Rewiew, Kovenharn, Aelnoths Katolsk Historisk forening for Danmark, 2003.

Cartas de Indias, México, sHCP, Facsímile de 1877, 1980, 172.

Cuevas, Mariano, Historia de la Iglesia en México, 5 vols. TlalpamE1 Paso: Imprenta del Asilo Patricio Sanz, 1921-1928.

García Icazbalceta, Joaquín, Don fray Juan de Zúmarraga, México, 1881; México, Editorial Porrúa, 1988.

Instrucciones que los Virreyes de Nueva España dejaron a sus sucesores, México, 1873. Nueva edición, Instrucciones y memorias de los virreyes novohispanos, México, Ed. Ernesto de la Torre Villar, Porrúa, 1991.

IRIARTE DE AsPURz, Lázaro, La aportación extranjera a las misiones españolas del patronato regio, Madrid, 1946.

Jørgensen, Kaare Rübner, "Broder Jakob den Danske, myter og realiteter”, Danish review for Church History: Kirkehistoriske Samlinger, 2010.

LeÓN, Nicolás, comp., Documentos inéditos referentes al ilustrísimo señor don Vasco de Quiroga, existentes en el Archivo General de Indias, México, Robredo, 1940. , El Ilmo. Sr. D. Vasco de Quiroga..., Morelia, Ed. de la uMs$\mathrm{NH}, 1984$.

LinDBæK, Johannes, De danske franciskanerklostre, Copenhague, 1914.

Mendieta, Gerónimo de, Historia Eclesiástica Indiana, Madrid, BAE, 1973.

Miranda Godínez, Francisco, Don Vasco de Quiroga y su Colegio de San Nicolás, 2a. Ed., Morelia, 1990.

Monasterio, Arturus, ofM, Martyrologium Franciscanium, París, 1653.

Morató Balletbó, Teresa, Fray Jacobo Daciano (defensor de los derechos religiosos de los indios), Tesis Doctoral inédita, dirigida por Carlos Martínez Shaw en la Universidad Nacional de Educación a Distancia, Facultad de Geografía e Historia, Madrid, España, 2007. 
Muñoz, fray Diego, "Memorial de la Provincia de San Pedro y San Pablo de Michoacán”, Archivo Iberoamericano, Madrid, 1922. El texto puede verse también en J. Benedict Warren, Michoacán en la década de 1580, Morelia, Universidad Michoacana de San Nicolás de Hidalgo, 2000.

Rasmussen, Nybo Jørgen, Fray Jacobo Daciano, Zamora, El Colegio de Michoacán, 1992. , Broder Jakob den danske, Kong Christian II yngre broder, Odense, Universitet forlag, 1986.

, "Replik til Kaare Rübner Jørgensen”, Danish review for Church History: Kirkehistoriske Samlinger, 2010.

, "Respuesta a las objeciones de Kaare Rübner Jorgensen", Xipe Totek, Revista Trimestral del Departamento Filosofía y Humanidades ITESO, Guadalajara, vol. xx, núm. 2, 30 de junio de 2011, 155-174.

Ricard, Robert, La conquista espiritual de México, México, Jus, 1947.

Romero Vargas, José, Fray Jacobo Daciano, Zacapu, Ediciones de Testimonio, 1966.

Rubio y Moreno, Luis, Pasajeros a las Indias I, Madrid, 1920.

Stangerup, Henrik, Fray Jacobo, Novela histórica, Colección andanzas, Barcelona, Tusquets Editores, 1993.

Torquemada, Juan de, Monarquía indiana, $1^{\text {a }}$ ed., Sevilla, 1615. Facsímile, México, Ed. Porrúa, 1969.

FeCHA DE RECEPCión DEL ARTículo: 17 de junio de 2008 FECHA DE ACEPTACIÓN Y RECEPCIÓN DE LA VERSIÓN FINAL: 26 de enero de 2011 